\title{
WORK-LIFE BALANCE: A STUDY IN THE PETROLEUM INDUSTRY
}

\author{
JUDY DE VILLIERS \\ ELIZE KOTZE \\ Programme: Leadership in Performance and Change \\ Department of Human Resource Management \\ Rand Afrikaans University
}

\begin{abstract}
A qualitative study was completed to discover how employees of a company in the petroleum industry define and experience the phenomenon of work-life balance, to identify the workplace determinants of work-life imbalance and to elicit some solutions for the problem. It was found that work-life balance is a personal issue that varies across time and situations and the underlying conflict experienced pertains to role overload and role interference. The most significant work-life conflict arises from complex workplace issues, including managing change, supervisory and technical competences, leadership, roles and accountabilities, and culture. Solutions to address the workplace issues, as well as the development of individual balance-enabling skills, are suggested.
\end{abstract}

\section{OPSOMMING}

'n Kwalitatiewe studie is onderneem om vas te stel hoe die werknemers van 'n maatskappy in die petroleumnywerheid die fenomeen van die werk-lewe ewewig definieer en ervaar, om die werkpleksdeterminante van ' $n$ werk-lewe onewewigtigheid te identifiseer en om sekere oplossings vir die probleem aan die hand te doen. Dit is gevind dat werk-lewe ewewig ' $n$ persoonlike saak is wat oor tyd en omstandighede varieer en die ervaarde onderliggende konflik na roloorladingsrolle en -inmenging verwys. Die mees betekenisvolle werk-lewe konflik tree na vore vanuit komplekse werkplekaangeleenthede, insluitende die bestuur van veranderings, toesighoudende en tegniese vaardighede, leierskap, rolle en aanspreeklikheid, asook kultuur. Oplossings om die werkpleksake aan te spreek, asook die ontwikkeling van individuele vaardighede om 'n ewewig teweeg te bring, word voorgestel.

Employees have an increased concern about balancing their work and personal lives (Grant-Vallone \& Donaldson, 2001). This is the result of a world of work characterised by change and increased demands on time, energy and work commitment (Burke, 2000). Furthermore, the concern is not limited to a specific group of employees as research in industrial countries has shown that employees across different organisational levels and with different family structures are concerned with achieving a better balance between working life, family obligations, leisure and socialising (Papalexandris \& Kramar, 1997). An inability to create a balance between work and personal life could influence employees' effectiveness and productivity in the workplace (Elloy \& Smith, 2003). Consequently appropriate employer initiated responses to this issue are of great importance.

A problem with the balance between work and personal life (hereafter being referred to as work-life balance) has been identified in employees in the Southern African division of a multinational petroleum company, of whom $75 \%$ of staff are located at the head office in Cape Town. In its bi-annual employee opinion survey of 2002 only $45 \%$ of employees in this company responded favourably to questions in the work-life balance category, compared to the $56 \%$ of an external benchmark, the Global High Performance Norm, which consists of international high performance companies with a reputation for excellence in people management practices. This difference was statistically significant. Furthermore, work-life balance was the only category in which there was not a significant improvement in the 2002 results as compared to the 2000 survey. Consequently it was important for the South African office to develop a deeper understanding of the problem of work-life balance and to identify the antecedents to the problem. The present research is an attempt to assist the company in this regard.

\section{Literature review and definition of core concepts}

Traditionally, research in the area of work-life interaction was primarily concerned with the increased number of working mothers managing the conflict between their work and family

Requests for copies should be addressed to: J de Villiers, Department of Human Resource Management, RAU University, PO Box 524, Auckland Park, 2006 roles and the consequent impacts on them and their families. This has resulted in a body of work-family interaction literature. However, because of the increased demands of jobs and changing social expectations (Burke, 2000; Aaron-Corbin 1999), it is recognised that balancing issues are important for all employees regardless of gender or parental status (Duxbury \& Higgins, 2001; Grant-Vallone \& Donaldson, 2001) and the research area has subsequently expanded to incorporate the wider population and broader non-work life activities beyond the family (Burke, 2000; Duxbury \& Higgins, 2001; Rayman, Bailyn, Dickert, Carre, Harvey, Krim \& Read (1999); Whitehead, 2002).

Studies in the area of work-life interaction have so far mainly concentrated on the conflict between people's work and other life roles. It is generally accepted that there is a clear link between work-life conflict and work-life balance, as attaining work-life balance is dependent on managing or reducing the conflict between various roles. From the literature referring specifically to work-life balance, the concept could generally be described as successfully balancing the needs arising from work and other life roles (definition informed by Aaron-Corbin, 1999; Whitehead, 2002). However, in order to understand work-life balance, it is important to first consider the possible underlying conflict between various life roles.

The study of work-life conflict has been predominantly approached from the role theory perspective (Perry-Jenkins, Repetti \& Crouter, 2000) and utilises the concepts of role conflict, role overload, and role interference. Role conflict occurs when the collective demands of individuals' various roles are in some sense incompatible so that participation in one role is made more difficult by participation in the other role (Duxbury \& Higgins, 2001; Grant-Vallone \& Donaldson, 2001 Greenhaus \& Beutell, 1985). Role conflict could include role overload as well as role interference (Duxbury \& Higgins, 2001). Role overload occurs when multiple demands exceed resources (Elloy \& Smith, 2003). Role-interference could occur in either direction, that is, requirements from the work role could interfere with the other life roles; similarly, the requirements of non-work roles may, in turn, impact on individuals' work responsibilities (Duxbury \& Higgins, 2001; Greenhaus \& Beutell, 1985; Rotondo, Carlson \& Kincaid, 2003). 
Furthermore, role conflict could also be construed in terms of the objective and psychological impacts that are experienced (Duxbury \& Higgins, 2001; Greenhaus cited in Grant-Vallone \& Donaldson, 2001). Individuals experience objective conflict when dealing with the everyday practicalities associated with limited time and conflicting schedules, while the psychological impacts refer to the perceptual aspect of feeling overloaded, highly stressed and overwhelmed by multiple commitments (Duxbury \& Higgins, 2001).

\section{Determinants of work-life conflict}

The origin of work-life conflict is a legitimate issue. Authors have various explanations for the determinants of this kind of conflict. Greenhaus and Beutell (1985) suggest that conflict occurs when either time devoted to the requirements of one role, or strain from participating in a role or finally, specific behaviours required by a role, make it difficult to fulfil the requirements of another. Moreover, conflict intensifies when roles are salient, central to the individual's self-concept or when there are negative consequences for not meeting role demands.

In a more recent study, Carlson, Kacmar and Stepina (1995) propose that in addition to time-based conflict, social identity should be considered concurrently. They found that as time spent in the work role and the identity that an individual derives from the work role became incongruent, the conflict increased. Furthermore, individuals who have strong identities with either role, or significant identities in both the work and non-work roles, experience more role conflict.

$\mathrm{Fu}$ and Shaffer (2001) distinguish between two different directions of role interference, namely family-to-work and work-to-family interference. The determinants for the first type arise from the family domain whilst work-to-family interference arises from the work domain. They suggest that the determinants are unique to the six dimensions of workfamily conflict (namely, work-to-family time-, strain- and behaviour-based conflict and family-to-work, time-, strain- and behaviour-based conflict). They found that determinants arising from the work domain have much stronger effects and are significant contributors to time- and strain-based work-tofamily conflict. Supervisor social support was found to reduce strain- and behaviour-based work-to-family conflict. The only significant determinants arising from the family domain are parental demands and hours spent on household work and these are correlated with time-based conflict solely. Fu and Shaffer's (2001) models that reflect the bi-directional and multi-dimensional aspects of work-life conflict appear in Figure 1 below.

Other international research on the determinants of work-life conflict includes an early study conducted by Pleck, Staines and Lang (1989) who concluded that certain job characteristics were strongly correlated with work-family conflict. These included the number of hours worked, irregular starting times, frequent and uncontrollable overtime work, an inflexible work schedule and physically or psychologically demanding work. Burke (1997), on the other hand, found that organisational values, associated with high performance and involvement, created an environment that may make it more difficult for employees to achieve or even wish to achieve balance in their work and life roles. Apart from the job characteristics and organizational values mentioned above, Papalexandris and Kramar (1997) stated that individual variables could also influence work-life balance. These included age, sex, qualifications, pay, professional aspirations and family status as well as attitudes, expectations and priorities assigned to the various roles by both partners. Finally, Duxbury and Higgins' (2001) found that the greater number of roles that individuals have, the more likely that they will experience high role overload. Amongst these, married individuals with children or eldercare experienced the highest conflict.
In contrast to the rich source of international research, there are only a limited number of studies on work-life conflict or balance in the South African context. Moreover, the majority of the research focuses on females' experiences.

There seems to be some contradiction regarding the amount of role conflict that females experience. On the one hand, Brink and De la Rey (2001) studied work-family conflict of successful employed women and found although respondents could describe strain and frustrations, the general measure of workfamily interaction strain was not high. These results supported those of Redelinghuys, Botes and De Wet's (1999) study on females in a commercial banking group. They also found that the respondents did not experience acute role conflict. It was further concluded that although most of the pressure experienced by the research group originated in the work role, the parental role had the greatest potential to create conflict.

Whereas the two studies mentioned above could create the impression that role conflict is not such a big issue, Jano (2000) established that professional women in households where both spouses pursue careers did indeed experience worklife role conflict. Their experienced conflict originated from their participation and value expectations being mainly concentrated in their work roles, whilst they felt more committed to some of their other life roles. Whitehead's study (2002, p.92) of life balance of professional women concurs in that the respondents did feel pressure because of the conflict ("role conflict was dynamic and a constant challenge") but it occurred at different levels and the minimum level of comfort varied for individuals. Furthermore, the study found that individuals perceived and defined balance differently and that life balance appeared to be cyclical and a process of ever changing experiences over time and life stages. Such differences in perception and definition of the concept might offer some explanation for the discrepancy in the findings of Brink and De la Rey (2001) and Redelinghuys (1999) versus Jano (2000) and Whitehead (2002). Furthermore, the different subject groups under study might have contributed to the inconsistency of the results.

The theoretical discussion above emphasises the importance of role conflict within the framework of work-life balance. Consequently, research on employees' experiences of work-life balance would inevitably necessitate an understanding of the underlying role conflicts experienced by them, as well as uncovering the organisational determinants that create imbalance. Therefore, the aim of this study is to determine how employees define and experience the phenomenon of work-life balance, to identify the workplace determinants of work-life imbalance for the specific company and, finally, to elicit some solutions for the problem.

\section{METHOD}

A qualitative approach was decided upon, as this approach is specifically suitable when the research takes place in a natural setting such as was the case with the petroleum company. Moreover, qualitative research attempts to make sense of and interpret constructs and phenomena in terms of the meanings that people ascribe to them; thus seeking to give meaning to social experience (Denzin \& Lincoln, 1998). Consequently this method will support the aim to tap the research participants' subjective experiences of work-life balance.

The study was exploratory in that the work-life balance dilemma in South Africa is a relatively under-researched area and this research endeavours to gain new insights into the problem. However, the study can also be regarded descriptive, as it intended to describe the subjective experiences of employees of the petroleum company as accurately as possible in terms of separate variables and characteristics (Mouton \& Marais, 1990). 


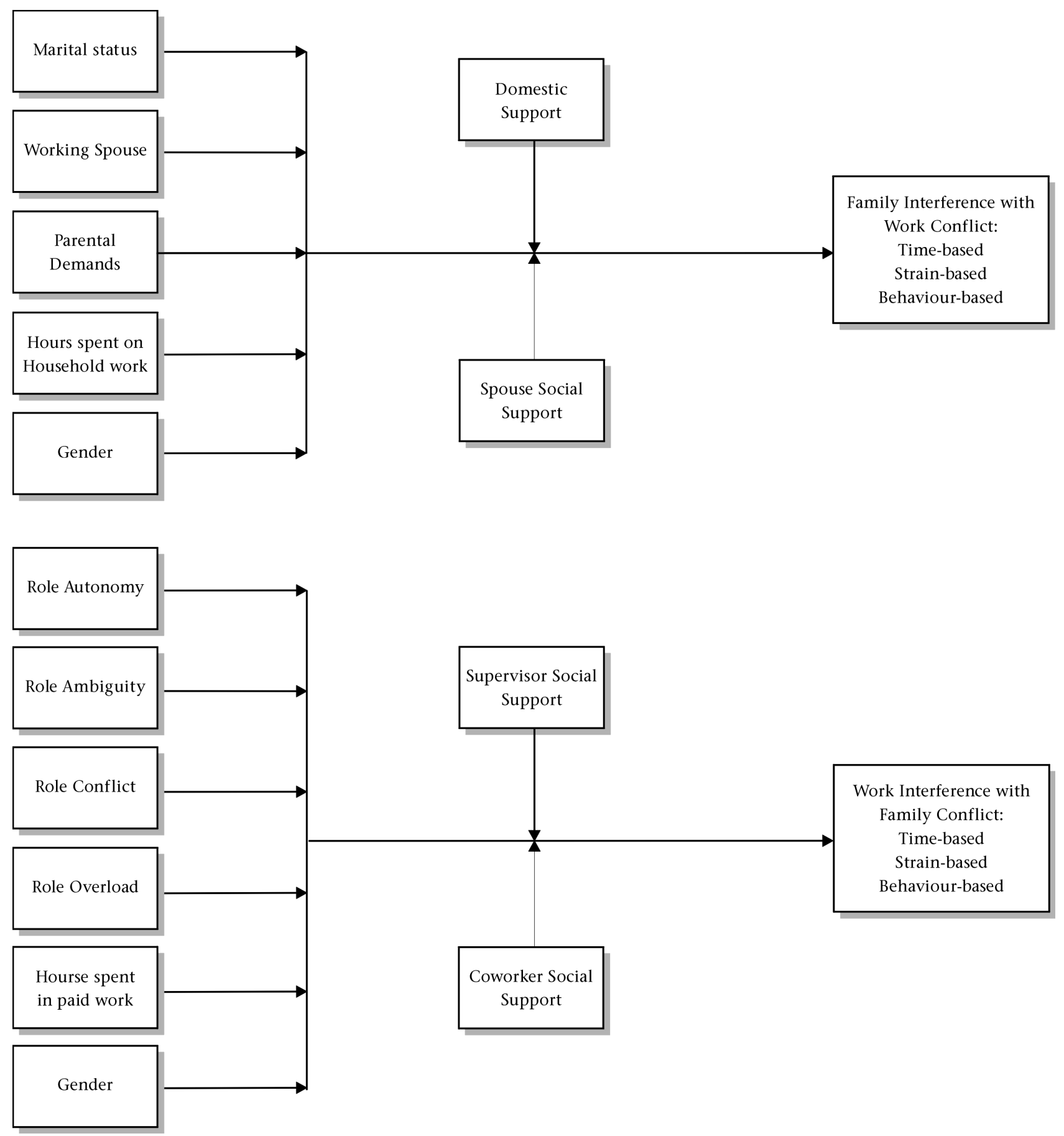

Figure 1: Models of the determinants of family interference with work (FIW) and work interference with family (WIF) conflict

\section{Setting and Participants}

The business area selected for research was the Finance Department of the South African Division of a multinational Petroleum Company, consisting of 92 employees organised in 11 teams according to their functions. The reasons for selecting this business area include that in the 2002 employee opinion survey, only $40 \%$ of employees from the Finance Department responded favourably to the work-life balance category - a substantial decrease since the 2000 survey result of 59\%. Furthermore, during the Company's 2002 Finance Conference, work-life balance was singled out as one of the top priorities to tackle during 2003.

Purposeful sampling was used to select 20 employees as participants for the study. To control for individual variables, they were selected on the basis that they had an immediate family, that is, a spouse/partner and/or children, were within the age group of 35 to 45 years old and occupied a position in the
C2 to D3 levels of the Paterson grading. Only seventeen employees were identified using these selection criteria, which was considered too small a sample. Expanding the age range to 27 to 52 years identified another four participants. Furthermore, the sample was checked to ensure that it included representatives from all teams within the Finance Department.

Eighteen of the participants had parental responsibilities and all but one participant had a spouse/partner. The sample was diverse in terms of ethnic group and gender, namely twelve Coloured, one African and seven White persons. Thirteen males and seven females were interviewed.

\section{Procedure}

Participants were sent an e-mail explaining the context and purpose of the study and requesting a one-hour interview. All but one employee agreed to participate. Interviews were conducted over a four-week period to gather data on employees' 
subjective experiences of work-life balance. At the onset of each interview, participants were reminded of the context and purpose of the study and assured that their input would remain confidential. Permission to tape the interviews was obtained from the participants, and the interviews were transcribed afterwards to facilitate analysis.

An interview schedule was prepared to give structure and guidance to the interviewer (Stroh, 2000). The schedule acted as a prompt and consisted of three broad topics outlined below.

- What work-life balance means to the individual; is it viewed as problematic for them and if so, what are some of the issues with which they are dealing? (Probes relating to stress, pressure, role overload and direction of role interference experienced were prepared.)

- What are the workplace factors contributing to work-life conflict?

- What are possible solutions to the problem as seen by the participants.

\section{Data Analysis}

This study followed an overall inductive approach, seeing it was without an explicit conceptual framework and did not embark on hypothesis testing (Mouton \& Marais, 1990). However, prior research guided the research as the researcher probed the participants for constructs found in the literature, such as role overload, role interference and direction of role interference.

In line with an inductive approach, a reiterative process of analysis was followed to gain insight and understanding into the work-life balance dilemma. Informal strategies of analysis were employed as the data was classified and categorised according to similarities and differences found, as well as searching for underlying patterns and themes (Schurink, 2002). The analysis involved identifying units, segmenting the data and making the relevant connections (Denzin \& Lincoln, 1998). The process followed was based on Stroh's procedure (2000), which included highlighting phrases and concepts that recurred in the text, comparing and linking the highlighted phrases and concepts in order to name them and begin a process of coding and finally, linking the codes together to determine the emerging themes. A continual reassessment took place to verify the emerging themes and sub-themes.

\section{RESULTS}

Several themes and a number of sub-themes emerged from the data analysis pertaining to the three broad research topics for this study. The themes and sub-themes are supported in the discussion below by extracts from the interviews.

\section{The subjects' experience of work-life balance}

As the company survey indicated a problem with work-life balance amongst employees in the Finance Department, it was, in the first instance, important to determine the participants' experience of the problem and how they defined work-life balance. Seven themes emanated from the participants' descriptions of their experiences of work-life balance. These themes could be labelled definition of work-life balance, uniqueness of the experience, significance of work-life balance, role overload, role interference, prioritisation of roles and finally, trade-offs and paybacks.

\section{- Definition of work-life balance}

The concept "work-life balance" had different meanings for different individuals. However, there seems to be agreement that work-life balance entails three characteristics. In the first instance it creates the opportunity to control one's own time ("Work-life balance is about timing: the amount of time at work, versus amount of time at home versus the amount of time at home spent on work"). In the second instance the concept was described as an opportunity to spend time at work on non-work (and non-stress creating) activities such as using the company gym and building individual and team relationships ("I am getting time off for teambuilding at times when we are not so busy and if you look at it holistically - it takes away from that total stress all the time"). The third characteristic ascribed to such balance is that it gives equal importance to all life roles ("Work-life balance means being able to achieve my optimal potential both in my work, family and with my friends whilst enjoying myself on each one of these interactions. I want to achieve in all areas").

\section{- Uniqueness of the experience}

When describing their experiences, participants spontaneously expressed opinions about individual ownership and individual experience relating to the work-life balance dilemma. Typical responses were: "Work life balance impacts on the individual each individual will experience it and deal with it differently"; "Work-life balance is really a personal choice - you have to make the decision of when to draw the line" and "It is a function of individual personality and individual response to the company environment".

Aligned with the individual ownership, employees referred to individual coping techniques that they used with varying success. Generally, successful techniques included refusing to accept additional work tasks ("Sometimes I have to say: 'enough is enough'), managing stress ("The gym really helps to let off all that stress"), gaining understanding and support from work and home by communication and being "more conscious of how one spends time at work." Other individual coping techniques that participants were aware of, but some had difficulty putting into practice, included being able to change roles effectively ("I have tried to leave work at a reasonable time and I find it increasingly hard to do so"), training staff, delegating more and effective prioritisation ("I find it problematic prioritising. If only I could walk in and do what I want to do").

\section{- Significance of work-life balance}

Some participants experienced work-life balance as a serious problem, whilst for others it was of little concern ("Personally in my life, it is a very big issue" versus "For myself - it is not a basic problem"). Participants, who experienced their work-life balance as a concern, generally reported that, although they could cope reasonably well with it, there were times that became problematic ("There are certain times where there is going to be an imbalance between work and life balance and there will be times again when you will be able to cope"). It also happened that at some stage in the participants' working lives, work-life balance had presented significant problems, however, they had now made a conscious effort to manage and control it "Two years ago, I suffered a lot of stress, I actually sought help - now I manage it better and am more relaxed about it.").

\section{- Role overload}

Many employees experienced that their work roles were overloaded. They expressed this as feeling pressured with too many demands at the same time ("Too many things on the go got me annoyed"), being too rushed, and not being able to complete all necessary work tasks, solve problems and train staff. In general interviewees did not feel that their roles outside of work were overloaded. However, employees with very young families found that their household and child rearing chores together with social events left little time for relaxing ("The family is important and takes up a large portion of the time. It is the time of our lives - we have very little time to sit down and read or for sports or hobbies").

\section{- Role interference}

The responses gave strong evidence of work-to-life interference. It was mainly described in terms of time-based conflict (Greenhaus \& Beutell, 1985) in that research participants 
experienced a disproportionate amount of time spent at work or on work-tasks at home. Additionally, there was also evidence of work-to-life strain-based conflict (Greenhaus \& Beutell, 1985) in that at times, participants could not stop thinking of work due to unsolved problems ("My husband used to tell me that I talk in my sleep and he would be able to tell me things that I had said about my job"; "I can't really switch off when I get home"). Further evidence of strain was that some respondents felt tired or exhausted at home ("I am quite exhausted when I get home, then basically have got three hours for the kids - then I just conked out") and experienced health problems ("I have problems sleeping"; "My eyes burn over quarter end"). No evidence of behaviour-based conflict could be identified during the interviews.

Strong evidence of work-to-life interference also emerged from the reaction of the participants' families. One male reported: "There is always that feedback loop. My child actually said 'I never see you except when it is dark, I never see you in the light' and then more recently he said to me 'You are always sleeping and working, there is no other time." A female interviewee stated "I only became aware how much it impacted on my daughter when she did not want to go to school. She started not doing so well at school and I had to take her to a psychologist and you wonder if is it worth it?"

Evidence of significant life-to-work interference was not apparent, but rather scenarios of supportive home-lives and families were portrayed. A research participant declared, "My strongest support is the family; and here what is important is trust, understanding and communication".

\section{- Prioritisation of roles}

A male research interviewee who felt that "Work-life balance was not a real problem" attributed this to "being able to change roles easily" and "getting the mixture right - got to know where the fundamental focus is." Another male participant with various interests outside of work and a balanced life stated "Always, the key thing for me is that when you are at work, you focus on work and when you are at home, you focus on home and when you play sports, you focus on that." A further male subject who described himself as ambitious and worked long hours declared "You have to satisfy yourself that the less important role was displaced - not the most important." A female employee for whom work-life balance was not a concern and indicated that she would like to spend more time at work but had to leave work at 4:30 pm to fetch her children, placed prime importance on her parental role.

The data suggest that research participants who were able to prioritise their roles and separate their various roles experienced a greater balance between their working and private lives regardless of their number of roles. Furthermore, participants with significant roles or interests outside of work were able to separate roles more easily than those who did not have significant roles or interests outside of work.

The ability to prioritise roles appears to be linked to individuals' values and aspirations and the varying importance they attributed to the work and non-work roles. A research participant experiencing acute work-life conflict for a prolonged period of time explained that in terms of her career aspirations she "had something to prove to herself" but had started "to question her values and priorities". Another participant stated, "It is about aspirations and expectations."

\section{- Trade-offs and paybacks}

Interviewees regarded work-life balance as a matter of trade-offs and paybacks. Long hours and regular deadlines were regarded as normal for a Financial Department and "needed to be managed otherwise one should not be working in the financial environment." The trade-offs of long hours and increased pressure around deadlines were tolerated in turn for being viewed as a responsible and valued member of the finance community (not "letting down" one's team), career advancement and a sense of personal achievement. The subjects also mentioned several circumstances, which they regarded as unacceptable trade-offs, namely

1. High demands and high overtime sustained over a long period of time with no recovery time ("It becomes a problem when it becomes a norm to work overtime. I don't have any leisure. Even on weekends I log in to try to keep up with emails").

2. Exceptionally long hours required over a limited time scale ("Normally I don't mind overtime at quarter ends, but the one at year end was an exception. That was just horrible. I think I put in 100 hours overtime over a two week period").

3. Perceived lack of control over the long hours and no clear vision for improvement from management ("I constantly warned him that we were going to have problems at quarter end, but once again no-one listened. You don't mind taking on certain things, but there was no clear indication that things were going to improve in the future").

4. Perceived lack of rewards in terms of career advancement, recognition and thanks ("It is also about reward - what people are expecting from work and that is going to influence how they see their work-life balance").

5. Perceived lack of support from their line managers ("It makes a difference - just want them to ask how it went or say something such as 'Did you have any problems?")

6. Visible impact on employees' families ("And then it started impacting my family and I decided that it was not worth it").

7. Visible impact on employees in terms of health and wellbeing ("I noticed that the previous few quarter ends - I was ill with bronchitis or tonsillitis").

8. Annual leave, sick leave or public holidays could not be taken ("There are times when it hits you more, and that is when you want to take annual leave").

In summary, the results for individuals' experiences of worklife balance indicate that for the majority of the subjects, the direction of the largest impact is from work-to-life roles. Work-life balance is viewed as manageable, however, the level of balance experienced is variable and is influenced by specific events and occurrences, such as tight deadlines. In this group, it was apparent that none of the varied responses could be attributed solely to gender, but were influenced by individuals' prioritisation of roles, values and aspirations. The core message from interviewees was that they were managing to achieve a balance, however, it was not always ideal and there were limits as to how much role conflict they would tolerate. Even though the themes described above emerged when research participants were discussing their experiences of work-life balance, they clearly overlap with the determinants of work-life balance.

\section{Workplace determinants of work-life conflict}

From participants' descriptions of their experiences, it became evident that they experienced a significant amount of work-tolife interference (Fu \& Shaffer, 2001). They were then further probed regarding the possible organisational factors responsible for this interference. Four themes emerged which seem to indicate workplace determinants. They could be labelled as the impact of change, inadequate human resources, lack of clear processes, roles and accountabilities, and the perceived Finance Department's culture.

\section{- Impact of change}

All employees could talk of a time when their work-life balance was significantly better or worse. Generally, during times of change in the work domain, interviewees felt a significant imbalance in their lives owing to the increased work demands.

Almost every research participant commented on the current increased workload to be delivered in tighter time frames caused by a number of significant changes emerging from 
both the local company's and the multinational's environments. A sub-theme identified was the lack of effective change management, which amplified the increased work demand. Participants related stories about insufficient planning and an under-estimation of the impact of the changes on finance processes. Furthermore, employees felt a general lack of involvement and control in the decision-making process influencing the change. This resulted in individuals being reactive and operating in uncertain and pressured environments. Participants stated: "Decisions get handed down and the consequences are not thought through. This causes stress for staff and impacts on work-life balance" and "The management from the Finance Department accepted a lot of tasks and jobs from other departments which we were not equipped to do - it was a nightmare".

\section{- Inadequate human resources}

Not having a sufficient number of employees and employees not having the required competences were viewed as key workplace contributors to work-life imbalance.

In terms of sufficient numbers of employees, participants felt that certain teams within the Finance Department were underresourced, which resulted in consistent high work demands and long hours. This became especially problematic when a team member was absent from work as there was no cover or relief. This, in turn, lead to increased workloads for the team members present at work and an increased workload when the absent employee returned to work. One participant stated: "You take off two days and then the next four nights you stay here late - nobody does your work for you". The view of the participants was that they could not influence the insufficient staff numbers situation. Being under-resourced can impact on staff morale as explained by a participant: "I know that a lot of people feel that aspects of their job are not their core job. They have been told 'Sorry we are under cost constraints, so no extra staff. You have got to take it on.' This has caused anxiety and dissent".

With reference to inadequate competences, it was stated that there was a deficiency of supervisory competences, financial analytical and interpretative skills and insufficient knowledge of processes. This resulted in inefficiencies, incorrect processing and a substantial amount of re-work to correct mistakes. An interviewee stated: "Often I am given the wrong numbers; I have to resubmit the numbers and that is where I waste a lot of time. We work a lot of overtime. The bulk of the problem is caused by people who do not know what to do."

Causes of inadequate competences were attributed to cost constraints, time constraints for training and learning, misplaced recruiting ("Not putting the right person in the right job") and inadequate handovers with a consequent loss of key knowledge. A participant explained: "People come into Finance completely blind. Their predecessors have left or are not interested and so people have taken over jobs with half the knowledge, and this shows, because we are always fixing messes from three to four years ago that people did not pick up then."

- Lack of clear processes, roles and accountabilities

Research participants referred to a lack of clarity and the prevalence of complicated finance processes. The lack of clear roles and accountabilities relating to these complicated processes further compounded this problem. The result was confused responsibilities between the teams in the Finance Department, lack of ownership of problems, inefficiencies and re-work. Participants felt that there was a disproportionate workload amongst teams and intra-team conflict was experienced. This contributed to increased work demands and longer hours as well as increased strain. A participant suggested: "Clarify roles and responsibilities. Work is lying in the wrong areas and if we could streamline this, it might reduce some stresses and strains in some departments."

\section{- Perceived Finance Department's culture}

A common belief amongst employees in the Finance Department was that working extra-ordinary hours (for example, working through the night) was viewed as a way of impressing managers and fellow colleagues ("... was a talking point in the department for months"). It created the impression of being ambitious and hardworking, and could thus facilitate career progression to leadership positions. A number of participants referred to the perception that employees who worked normal hours were viewed as less dedicated and hardworking. It was almost as if this particular department nurtured a sub-culture that interfered with work-life balance. "The culture that to get to the top you have to work 24 hours a day - that has got to go and it has not gone yet. We get some leaders from overseas that brag about how little time they have at home. They indicate that they work 24 hours a day and they brag about it like it is something special." This, in turn, had the effect that many interviewees stated that they felt guilty when applying company policy to take time off in lieu of overtime worked. Guilt was experienced because fellow colleagues watched the amount of time others worked and it was felt that managers did not actively encourage or support time off.

The issue of taking time off also had a further ripple effect to employees' annual leave. This related to not being able to take time off during periods when friends and family were on leave, for example, the December festive period, or public holidays. It was also difficult to take off a substantial period of time for recovery due to the monthly deadlines. A significant portion of employees had experienced their scheduled leave being cancelled or postponed and they related stories of when employees had been recalled from leave. Apart from the practicalities (such as not having sufficient cover and finding an appropriate quiet time in the year for taking leave), there were emotional impacts that prevented the leave taking. For example, employees were hesitant in applying for leave because they felt that line managers did not support leave-taking: "Your line manager looks shocked when you ask for leave" and "I always have to fight for my leave" were just two of the responses.

Throughout the interviews, the sub-theme of a lack of recognition and support for individuals and their needs emerged. The needs included effective leadership (clear direction, planning and proactive problem solving), recognition of time needed for rest, recovery and other life roles, and reward and recognition for their efforts and performance. Illustrations include: "Finance needs strong leadership with prioritisation and mentoring", "Last year was very busy and I did not have the Finance Manager's support. I had no resources and realised that I was not going to cope. I was told 'just see what you can do' and that wasn't the response that I wanted" and "Most people are family people but more are taking work home - working late at night. They are upset about it- because they want to be rewarded for it. Let management come out with an occasional thank-you letter."

A key message to managers was that employees are coping with their workloads but that does not mean that they accept it or that the paybacks of recognition and support are sufficient. Generally the workplace factors contributing to work-life conflict were viewed as beyond the individual's realm of control and responsibility and that finance leaders needed to act to rectify these issues.

\section{- Interviewee suggested solutions}

Research participants agreed that there would always be a degree of conflict between work and non-work roles and there was no clear way forward to fully resolve this issue. A participant declared: "Work-life balance is a problem. On the one side, it is a function of individual responses to the company environment and on the other, it is not something that is inherently resolvable". Nevertheless, employees could suggest solutions to enable individuals to cope better, as well as interventions to curb the impact of determinants from the work domain. 
Suggested solutions for individuals included learning balanceenabling skills such as effective planning and prioritisation, and improving technical financial and information technology competences to reduce inefficiencies. It was suggested that individuals should set individual work-life balance goals as part of their work targets, and should focus on attaining an acceptable balance by being self-aware ("You need to know what motivates you" and "Be more conscious; try to understand where does the time go to"). Finally, employees should create understanding at home and at work by communicating their role needs.

The majority of the offered solutions involved a response to the workplace factors interfering with work-life balance. These included clarifying processes, roles and accountabilities, advanced warning of changes impacting on the Finance Department, better planning, improving mentoring and support from line managers, and creating a leave-friendly and flexible environment. As part of this, employees suggested that the policy dealing with flexible working should be clarified. Supervisors in the Finance Department should become more aware of the issue of work-life balance. Line managers "should be observant and empathetic" regarding work-life balance and "not (to) give out negative messages to people when they need time out." Finally, they should recognise individuals for their efforts and personal life sacrifices.

\section{DISCUSSION}

The data gathered from individuals' subjective experiences of work-life balance will subsequently be discussed in terms of the aims of this article, namely to clarify how the participants described and experienced the concept work-life balance, what they perceived the workplace determinants contributing to imbalance were, and, in the last instance, their proposed solutions to the dilemma. In order to facilitate illumination of the social construction of the employees, experiences and views will also be related to existing empirical findings and relevant abstract theoretical concepts.

Work-life balance seems to be a very subjective concept, as it has different meanings for different individuals, and varies over time and situations. This agrees with Whitehead's (2002) findings that participants define life balance differently and that life balance is a personal experience. However, the majority of participants described work-life balance in terms of having available time to fulfil various roles, which suggested that, for those who had a problem with work-life balance, time-based role conflict (Greenhaus \& Beutell, 1985) was the predominant underlying conflict. The literature study revealed that role conflict could include role overload, as well as role interference. For the Financial Department's employees evidence existed that both role overload (Duxbury \& Higgins, 2001; Elloy \& Smith, 2003) as well as role interference (Duxbury \& Higgins, 2001; Fu \& Shaffer, 2001; Greenhaus \& Beutell, 1985; Rotondo et al, 2003) were present. The overload seemed to concentrate in the work role as the participants experienced that there was so much work that they always had to work overtime to get it done. This concurs with Pleck et al's (1989) conclusion that the number of hours, overtime and an inflexible work schedule are factors contributing to work-family conflict. Regarding the direction of role interference there is no doubt that, in the case of this specific department, it was a work-to-life interference (Fu \& Shaffer, 2001). Participants had to spend so much time on the work role that it affected their family roles. Consequently, those employees with young children experienced the overload more intensely. This is supported by previous research indicating that work-life balance issues are related to lifecycle stage and are more acute for parents of younger children (Duxbury \& Higgins, 2001; Greenhaus \& Beutell, 1985; Redelinghuys et al, 1999). Overall, this research thus supports Fu and Shaffer's (2001) findings that pressures from the work role have the strongest effects on work-life balance.
Responses mainly supported an objective conflict (Duxbury \& Higgins, 2001), as it was associated with the everyday practical challenges, such as deadlines and under-trained staff. However, indications of the psychological impact of the conflict were reflected in responses referring to the inability to switch off from work, exhaustion, and health problems. The psychological impacts appear to be related to the strain-based work interference with life conflict (Fu \& Shaffer, 2001).

Other individual issues that influenced work-life balance were the salience placed on roles, and the individual's ability to prioritise the roles. This concurs with role theory assumptions that role systems are inherently hierarchical and managing role conflict requires favouring one role over another (Thoits, cited in Perry-Jenkins et al, 2000). The findings also support prior research that found that the inability to prioritise one role over another might impact on work-life conflict (Carlson et al, 1995). However, the present research suggests the effect of a mediating factor, in that employees with significant outside of work roles found it easier to separate roles. This seems to contradict literature that suggests that the greater number of roles an individual has, the more likely they will experience high role overload (Duxbury \& Higgins, 2001).

Further support for the uniqueness of the experience of work-life balance could be deduced from the responses stating that worklife balance varies for the individual over time and situations. The results suggest that a degree of work-life conflict is tolerated until the trade-offs outweigh the paybacks and that the participants became aware of this when their families or personal health had been impacted. These findings support Whitehead's (2002) conclusion that life balance is viewed as a process consisting of ever changing experiences. It further agrees with recommendations that work-family conflict should be studied as a stress episode since individuals do not perceive work-life conflict immediately when conflicting demands are experienced but that it depends on the frequency of the conflicting demands and on the significance of the sphere that has been disturbed (Greenhaus \& Parasurman cited in Cinamon \& Rich, 2002).

In summary, one could conclude that work-life balance is a personal issue that varies across time and situations. However, the findings suggest that the most significant work-life conflict experienced (both time- and strain-based) arises from the workplace. Therefore, it becomes important to look at the determinants in the workplace that might be responsible for this conflict and the concurrent experience of work-life imbalance.

Several workplace determinants leading to a feeling of work-life imbalance could be identified from the responses. These were labelled as impact of change, inadequate human resources, lack of clear processes, roles and accountabilities, and the perceived Finance Department's culture.

The findings suggest that employees experienced considerable work-life conflict during times of change. Furthermore, significant changes, such as changed reporting processes, were common in both the local company's and multinational's environments. This concurs with literature that suggests the present-time difficulty in attaining work-life balance is caused in part by company responses to the heightened global competition, which results in restructurings and compacted work (Duxbury \& Higgins, 2001) and high performance organisations with increased performance pressures on employees (Burke, 2000). Furthermore, the present research indicates that the lack of effective change management compounded the problem. This appears to be related to the workplace determinant theme of inadequate human resources and in particular, the lack of supervisory skills.

In addition to the identified weakness of supervisory and technical finance skills, the findings indicate that the finance teams were under-resourced. This resulted in increased 
workloads and long hours, which impacted on staff morale. Decreased employee morale can impact on commitment and productivity and this concurs with Elloy and Smith's (2003) suggestion that employee productivity and effectiveness will be directly related to employees' ability to achieve work-life balance.

The results suggest that the work-life balance problem of the petroleum company is further compounded by the lack of clarity surrounding the complicated finance processes and the role ambiguity created by the lack of clear roles and accountabilities. It was found that the role ambiguity contributes to both time- and strain-based conflict. This agrees with Fu and Shaffer's (2001) model of the determinants of work interference with family conflict and reflects recent findings that work design characteristics were strong predictors of individual's sense of control and ability to maintain work-life balance (Batt \& Valcour, 2003).

The Finance Department was viewed as nurturing a culture that interfered with attaining work-life balance, as working long hours were perceived to facilitate career progression and taking time off for recovery was seen as unsupported by managers. These findings are supported by existing literature. Burke (1997; 2001) highlights the importance of having organisational values that endorse balance at the workplace and Rayman et al (1999) concluded that a Canadian financial services firm - where the culture contributed to a competitive, deadline driven environment - allowed limited opportunities for the integration of personal and work roles. Furthermore, the difficulty experienced by employees in taking leave reflects Perry-Jenkins et al's (2000) findings that informal barriers can exist that make it difficult for employees to take leave or for the period that they would like.

Finally, the results suggest that leadership, supervisor/manager recognition and support for individuals and their needs, influence work-life balance. This finding reflects Batt and Valcour's (2003) finding that support from supervisors for life balance is the most important component of work-life support. Furthermore, Coetzee and Vermeulen (2003, p. 48) identified "concern for employees" as one of the crucial supervisor characteristics that could enhance the commitment of workers. This entails that supervisors have to treat employees as people and not as factors of production, "... and let employees have a life outside work."

In summary one could conclude that workplace determinants discussed above have significant influences on employees' experiences of work-life balance and warrant attention from the Finance Department's leaders. Therefore, it was appropriate to question participants regarding possible solutions pertaining to the work-life balance dilemma.

The fact that participants agreed that there would always be a degree of conflict between work and non-work roles reflects Burkes's finding (2001) that what may hinder progress to address work-life balance issues, is that work and personal life are viewed as being either-or concepts. However, participants were able to suggest solutions that could be utilised by individuals to enable them to operate more efficiently and to manage their work-life balance more effectively, as well as interventions for the Finance Department.

A suggested solution for individuals was to create understanding by communicating role needs. This reflects Fu \& Shaffer's (2001) models of determinants, in that domestic and spouse social support mitigate the experience of family-to-work interference, whilst supervisor and co-worker social support impact on work-to -family interference. This is further supported in the findings as life-to-work interference was not apparent and scenarios of supportive home-lives and families were portrayed.
Overall, more solutions were offered on interventions for the Finance Department in response to the identified workplace determinants of work-life conflict, suggesting that this is where the greatest impact could be made. The desire was apparent for clear leadership and support from the managers to enable participants to cope with their roles more effectively. This suggests that coping with work-life conflict is not only related to an individual's capabilities, but also to the individual's control (or perception of control) over the situation. Research suggests that a high level of control enables individuals to cope with occupational stressors such as workload (Perry-Jenkins et al, 2000).

Finally, it is clear from the current research that the dilemma of work-life balance is not easy to rectify. Not only is it an individual concept that varies over time and situations, it is significantly impacted by complex workplace issues, such as managing change, supervisory skills, leadership and organisational values.

\section{CONCLUSIONS}

In conclusion, this explorative study suggests that employees' work-life balance should improve by nurturing individual balance-enabling skills as well as developing organisational balance-supportive capabilities. In line with this, the Finance Department should consider tackling the work-life dilemma on several fronts. Firstly, opportunities for individuals to enhance their work-life management skills should be created. This could occur via mentoring and coaching, as well as formal courses on time-management, planning and prioritisation, and stress management. Furthermore, the department should concentrate on developing effective and supportive managerial and leadership capabilities. Desired outcomes associated with this include building strong relationships and increased communication with employees in order to be aware of and support their role priorities. Thirdly, this research builds a case for the department to become operationally efficient as this significantly impacts on work-life balance. It should concentrate on the basic organisational building blocks, such as efficient processes, clear roles and responsibilities, effective resourcing, adequate employee development and change management capabilities. Finally, the Finance Department needs to carefully examine its culture and values to ensure that they are balance enabling. The culture should be supportive and flexible, and it should reward results, not time at work.

A limitation of this study is that it examines work-life balance at a particular point in time, despite indications that the phenomenon of work-life balance is a constantly changing social process. A further limitation is that the research was conducted in only one department of a specific organisation, and the results could thus not be generalised to other departments or organisations. Therefore, it is recommended that future research using multi-methods, including quantitative methods replicate this study over different and larger subject groups in corporate South Africa. Longitudinal studies would add significant insight to understanding individual's subjective experiences of work-life balance over time.

\section{REFERENCES}

Aaron-Corbin, C. (1999). The multiple-role balancing act. Management Review, 88 (9), 62-65.

Batt, R. \& Valcour, P.M. (2003). Human Resources practises as predictors of work-family outcomes and employee turnover. Industrial Relations, 42 (2), 189-220.

Brink, B. \& De la Rey, C. (2001). Work-family interaction strain: coping strategies used by successful women in the public, corporate and self-employed sectors of the economy. South African Journal of Psychology, 31 (4), 55-61. 
Burke, R.J. (1997). Culture's consequences: organisational values, family-friendliness and a level playing field. Women in Management Review, 12 (6), 222-227.

Burke, R.J. (2000). Do managerial men benefit from organisational values supporting work-personal life balance? Women in Management Review, 15 (2), 81-89.

Burke, R.J. (2001). Organisational values, work experiences and satisfactions among managerial and professional women. The Journal of Management Development, 20 (4), 346-354.

Carlson, D.S., Kacmar, K.M. \& Stepina, L.P. (1995). An examination of two aspects of work-family conflict: time and identity. Women in Management Review, 10 (2), 17-25.

Cinamon, R.G. \& Rich, Y. (2002) Gender differences in the importance of work and family roles: Implications for workfamily conflict. Sex Roles: A Journal of Research, 11, 531-554.

Coetzee, M. \& Vermeulen, L. (2003). Employee commitment: Are supervisors running a puppet show? Human Resource Future, June, 46-48.

Denzin, N.K. \& Lincoln, Y.S. (1998). Strategies of qualitative inquiry. Thousand Oaks: Sage Publications.

Duxbury, L. \& Higgins, C. (2001). Work-life balance in the new millennium: Where are we? Where do we need to go? Ottawa: Canadian Policy Research Networks Discussion Paper.

Elloy, D.F. \& Smith, C.R. (2003). Patterns of stress, work/family conflict, role conflict, role ambiguity and overload among dual-career and single-career couples: An Australian study. Cross Cultural Management, 10 (1), 55-66.

Fu, C.K. \& Shaffer, M. A. (2001). The tug of work and family. Personnel Review, 30 (5), 502-522.

Grant-Vallone, E.J. \& Donaldson, S.I. (2001). Consequences of work-family conflict on employee well-being over time. Work and Stress, 15 (3), 214-226.

Greenhaus, J.H. \& Beutell, N.J. (1985). Sources of conflict between work and family roles. Academy of Management Review, 10 (1), 76-88.
Jano, R. (2000). Role and career salience of dual career professional women. Unpublished masters thesis in psychology, University of the Western Cape, Cape Town.

Kossek, E.E. \& Ozeki, C. (1999). Bridging the work-family policy and productivity gap: A literature review. Community, Work \& Family, 2 (1), 7-32.

Mouton, J. \& Marais, H.C. (1990). Basic concepts in the methodology of the social sciences. Pretoria: HSRC.

Papalexandris, N. \& Kramar, R. (1997). Flexible working patterns: Towards reconciliation of family and work. Employee Relations, 19 (6), 581-595.

Perry-Jenkins, M, Repetti, R.L. \& Crouter, A.C. (2000). Work and family in the 1990s. Journal of Marriage and the Family, 62, 981-998.

Pleck, J.H., Staines, G.L. \& Lang, L. (1989). Conflicts between work and family life. Monthly Labor Review, March, 29-32.

Rayman, P., Bailyn, L., Dickert, J., Carre, F., Harvey, M., Krim, R. \& Read, R. (1999). Designing organizational solutions to integrate work and life. Women in Management Review, 14 (5), 164-176.

Redelinghuys, N., Botes, L.J.S. \& De Wet, M. (1999). Role conflict among women employees: Fact or fiction? Society in transition, 30 (1), 54-68.

Rotondo, D.M., Carlson, D.S. \& Kincaid, J.F. (2003). Coping with multiple dimensions of work-family conflict. Personnel Review, 32 (3), 275-296.

Schurink, W.J. (2002). Introducing Qualitative Research. Paper presented at the "Leadership in Performance and Change Doctoral Programme". Johannesburg: Rand Afrikaans University.

Stroh, M. (2000). Qualitative interviewing. In Burton, D. (Ed.). Research training for social scientists. London: Sage Publications.

Whitehead, T. (2002). Career and life balance of professional women in a South African context. Unpublished doctoral thesis in Leadership in Performance and Change, Rand Afrikaans University, Johannesburg. 